\title{
Effect of Excess Axle Loads and High Tire Pressures on Flexible Pavement Performance
}

\author{
Saad A. El-Hamrawy and Ahmed I. Abu El-Maaty, \\ Department of Civil Engineering, Faculty of Engineering, Minoufiya University, \\ Shebin El-Kom, Egypt.
}

\begin{abstract}
The main objective of this paper is to evaluate the performance of the flexible pavement under different conditions of axle loads and tire pressure of different vehicles (trucks) in Egypt.. Strains of different pavement sections were calculated using computer program based on linear elastic theory. Moreover, theoretical analysis was achieved by using BISAR computer program to obtain regression equations to simplify determination of load equivalency factor (LEF) as a function of axle loads and tire pressure for single and tandem axle loads. A comparison between the values of calculated LEF and these that adopted by the AASHTO specifications was achieved. From the results analysis, it could be obtained that, at low to intermediate axle loads, high tire pressure could cause marked increase in LEF. At high axle loads, variation of equivalency factor with tire pressure could be neglected. Moreover, increased subgrade elastic modulus had insignificant influence on LEF.

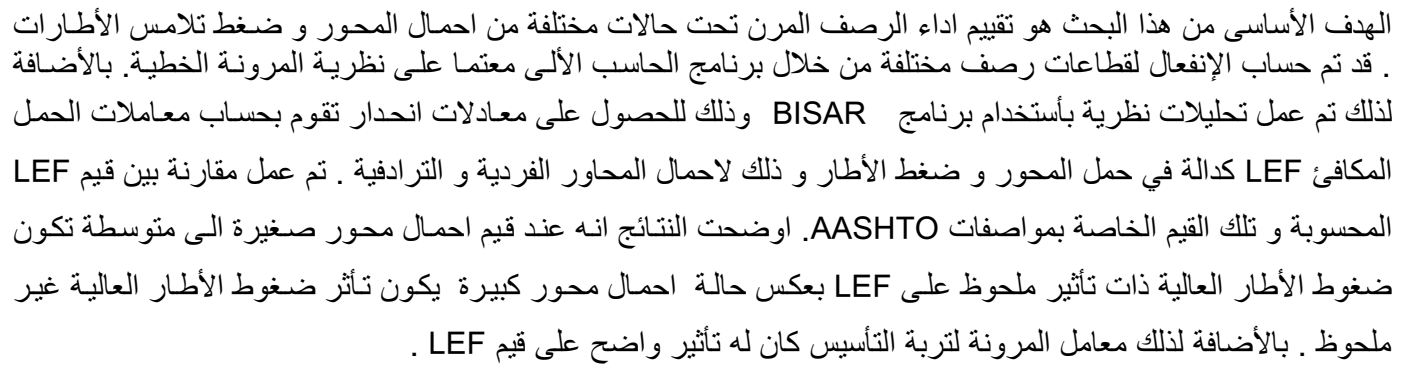

Keywords: Load equivalency factor ; Axle loads; tire pressure; flexible pavement; fatigue failure ; rutting failure.

\author{
Abbreviations \\ LEF : Load Equivalency Factor. \\ $\mathrm{Ef}_{\mathrm{t}}$ : Load Equivalency Factor due to Fatigue . \\ $\mathrm{Ef}_{\mathrm{c}}$ : Load Equivalency Factor due to Rutting . \\ $\mathrm{d}$ : Layer Thickness . \\ E : Elastic Modulus . \\ $\mu$ : Poisson's Ratio .
}

\section{Introduction}


The main reasons for highway damages can be manifold among mixture design, high temperature in summer, change in traffic load, etc. Recently, with the development of vehicles manufactures, many heavy trucks have spread all over the world. For example, in Egypt, there are many types of heavy vehicles of 6-axles of total weight ranging from 42 to 52 ton [1]. These heavy vehicles have a negative effect on pavement responses.

Premature failure of flexible pavements has more circulation in many roads in Egypt as a result of the drastic changes in truck axle loads as well as tire pressures [2]. Trucks play an important role in the pavement damage because they apply the highest loads to the road surface, which lead to pavement distresses . Therefore, it becomes necessary to study the characteristics of trucks (axle load - tire pressure) in order to evaluate their effect on the design of flexible pavement. To reflect the actual load application on pavements the effects of heavy axle load and tire pressure must be evaluated. The detrimental effects of high tire contact pressure on flexible pavement are examined by computing the tensile strain at the bottom of asphalt layer and the compressive strain at the top of subgrade.[3]

Salem [4] show that both fatigue and rutting lives have decreased dramatically by increasing the axle loads especially more than 13 tons. Morton et al. [5] found that truck tire inflation pressures have increased significantly over the last decade, with over $84 \%$ of all measures truck tire inflation pressures exceeded the generally accepted design norm of 700 $\mathrm{KPa}$.

\subsection{Flexible Pavement Design Criteria}

In pavement design and analysis, loads on the surface of the pavement produce two strains, which are believed to be critical for design purposes. These are [6]:

1. The horizontal tensile strain $(\varepsilon t)$ on the underside of the lowest asphalt-bound layer,

2. The vertical compressive strain $(\varepsilon \mathrm{v})$ at the top of subgrade layer.

If the horizontal tensile strain ( $\varepsilon t)$ is excessive, cracking of the surface layer will occur, and the pavement distresses due to fatigue. If the vertical compressive strain (Ev) is excessive, permanent deformation occurs at the surface of the pavement structure from overloading the subgrade and the pavement distresses due to rutting [6].

\subsection{Equivalency Factors Based on Fatigue Criteria}

According to Yung[7] and ZONG [8]. The equivalent axle load factor (LEF) on the basis of fatigue failure is :

$$
\mathrm{LEF}=\mathrm{Nfs} / \mathrm{Nfl}=
$$

$[\mathrm{k}(1 / \varepsilon \mathrm{tss}) \mathrm{m}] /[\mathrm{k}(1 / \varepsilon \mathrm{tij}) \mathrm{m}]=(\varepsilon t \mathrm{ij} / \varepsilon t s s) \mathrm{m}(1)$

Where:

Nfs: number of repetitions to failure of standard load and pressure; Nfl: number of repetitions to failure of arbitrary load and pressure; ctss: the maximum tensile strain at the underside of asphalt layer under the standard single axle load of $80 \mathrm{kN}$ and a tire inflation pressure of $80 \mathrm{Ib} / \mathrm{in} 2$; $\varepsilon$ tij: the maximum tensile strain at the underside of asphalt layer for the i axle load and $\mathrm{j}$ tire inflation pressure ; $\mathrm{m}$ : coefficient equal 5 according to Gomma [6].

\subsection{Equivalency Factors Based on Rutting Criteria}

The equivalent axle load factor (LEF) on the basis of fatigue failure is the ratio of NfS to Nfl.

$$
\mathrm{LEF}=\mathrm{Ncs} / \mathrm{Ncl}=
$$

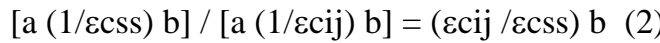

Where:

Ncs: number of repetitions to failure of standard load and pressure; $\mathrm{Ncl}$ : number of repetitions to failure of arbitrary load and pressure; ecss: the maximum tensile strain at the underside of asphalt layer under the standard single axle load of $80 \mathrm{KN}$ and a tire inflation pressure of $80 \mathrm{Ib} / \mathrm{in} 2$; $\varepsilon$ cij: the maximum tensile strain at the underside of asphalt layer for the i axle load and $\mathrm{j}$ tire inflation pressure ; b: coefficient equal 5 according to Gomma [6].

\section{Characteristics of Elastic Layered Programs}

Elastic layered analyses have been easily implemented and widely accepted. Although elastic layered programs have several advantages, they can not give accurate pavement responses. First of all, these methods assume that all layers are linear elastic but this assumption makes it difficult to analyze layered system consisting of nonlinear base/subbase and subgrade soil materials. Secondly, all wheel loads applied on top of the surface layer have to be axisymmetric, which is not true for actual wheel loads. At last, elastic layered programs assume isotropic material property that is not realistic for most geomaterials, especially not for unbound aggregate materials . Limitations like these are hard to show that realistic pavement responses can be predicted using elastic layered programs [9].

- 384 - $\quad$ Engineering Research Journal, Minoufiya University, Vol. 35, No. 4, October 2012 


\section{Results and discussions}

Finite element analysis has become commonplace in recent years. Numerical solutions to even very complicated stress problems can now be obtained routinely using finite element analysis and the method is so important that even introductory treatments of mechanics of materials such as these modules should outline its principal features [10].To calculate the total distress for the different layers of the pavement, the linear elastic computer programs as BISAR and ELSYM5 can be used for this purpose. Moreover, the modulus of subgrade reaction $(\mathrm{K})$ and elastic modulus (E) of one or multi- layers can be determined [10]. Moreover, a finite element programs as ABAQUS and FENLAP were used to model the pavement structure and predict the pavement distress (stresses-strains-deformation) at any point.

research the linear elastic BISAR computer program was selected to determine the pavement distress (stress-strains-deformation) under heavy axle weights and high tire pressures at any point.

\subsection{Points for Maximum Strains Determination}

The geometry of axle structure along with the locations for the determination of maximum strains are illustrated in Figure (1).
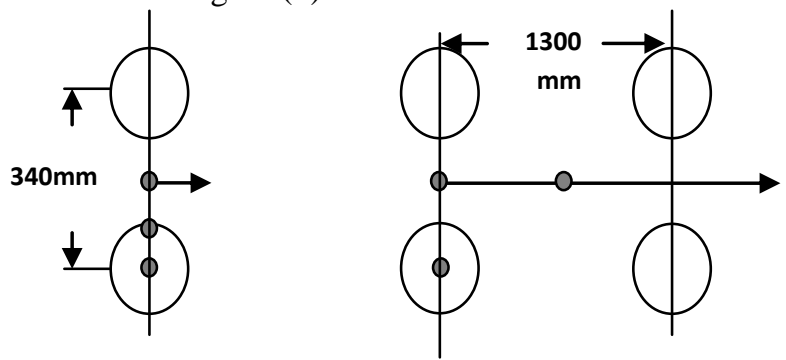

Figure (1): Geometry of Axle's Configuration .

\subsection{Pavement Cross Sections}

A typical pavement cross section was considered accordino to Ahd el Motaleh (2009) [111 This section ules should outline its principal features [10].To calculate the total distress for the different layers of the pavement, the linear elastic computer programs as BISAR and ELSYM5 can be used for this purpose. Moreover, the modulus of subgrade reaction $(\mathrm{K})$ and elastic modulus $(\mathrm{E})$ of one or multilayers can be determined [10]. Moreover, a finite element programs as ABAQUS and FENLAP were used to model the pavement structure and predict the pavement distress (stresses-strains-deformation) at any point. In this research the linear elastic BISAR computer program was selected to determine the

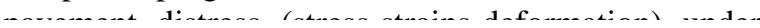
subgrade with elasticity modulus $(\mathrm{E} 3=58$ to 87 $\left.\mathrm{N} / \mathrm{mm}^{2}-\mu=0.45\right)$.

\subsection{Effect of Heavy Axle Load and High Tire}

\section{Pressure on the LEF}

In this point traffic is expressed in terms of repetitions of single axle load (from 35.6 to $160 \mathrm{KN}$ ) and tandem axle load (from 80 to $275.8 \mathrm{KN}$ ). As Abdel-Motaleb demonstrated [2], the dual tire is approximated by two circular plates (with variable radius according to axle load and tire pressure) and spaced at $340 \mathrm{~mm}$. center to center. The tandem axles are represented by two axles spaced 1300 center to center [2]. The tire pressure ranged from 0.5 to 1.1 $\mathrm{N} / \mathrm{mm} 2$ according to a field survey which has been carried out on Cairo -Suez road and Cairo Alexandria desert road [11]. The load equivalent factors (LEF) for both fatigue and rutting were calculated according to equations (1) and (2).

It can be observed from Tables (1) and (2) the effect of increased tire pressure on asphalt pavement depends on axle load. As the axle load increases, high

Table (1): LEF \&Tire Pressure for Single Axle Load with Dual Tires at E subgrade $=58 \mathrm{~N} / \mathrm{mm}^{2}$.

\begin{tabular}{|c|c|c|c|c|c|c|c|c|c|c|c|}
\hline \multirow{2}{*}{$\begin{array}{c}\text { Axle load } \\
(\mathrm{KN})\end{array}$} & \multirow[t]{2}{*}{ LEF } & \multicolumn{10}{|c|}{ Tire Contact Pressure $\left(\mathrm{N} / \mathrm{mm}^{2}\right)$} \\
\hline & & 0.50 & 0.55 & 0.60 & 0.70 & 0.75 & 0.80 & 0.85 & 0.90 & 1.00 & 1.10 \\
\hline \multirow{2}{*}{35.6} & ${ }^{*} \mathrm{Ef}_{\mathrm{t}}$ & 0.24 & 0.36 & 0.54 & 1.19 & 1.65 & 2.31 & 4.16 & 5.52 & 7.04 & 11.33 \\
\hline & ${ }^{* * *} \mathrm{Ef}_{\mathrm{c}}$ & 0.02 & 0.02 & 0.02 & 0.02 & 0.02 & 0.02 & 0.02 & 0.02 & 0.02 & 0.02 \\
\hline \multirow{2}{*}{71.2} & $\mathrm{Ef}_{\mathrm{t}}$ & 0.75 & 0.95 & 1.21 & 1.96 & 2.48 & 3.09 & 5.20 & 6.04 & 8.27 & 13.49 \\
\hline & $\mathrm{Ef}_{\mathrm{c}}$ & 0.57 & 0.57 & 0.57 & 0.59 & 0.60 & 0.59 & 0.58 & 0.59 & 0.59 & 0.61 \\
\hline \multirow{2}{*}{80.0} & $\mathrm{Ef}_{\mathrm{t}}$ & 1.00 & 1.26 & 1.58 & 2.41 & 3.01 & 3.69 & 5.58 & 6.82 & 8.44 & 14.69 \\
\hline & $\mathrm{Ef}_{\mathrm{c}}$ & 1.00 & 1.01 & 1.03 & 1.01 & 1.04 & 1.04 & 1.07 & 1.08 & 1.08 & 1.09 \\
\hline \multirow{2}{*}{106.8} & $\mathrm{Ef}_{\mathrm{t}}$ & 2.29 & 2.80 & 3.38 & 4.75 & 5.64 & 6.67 & 9.17 & 10.78 & 12.61 & 17.33 \\
\hline & $\mathrm{Ef}_{\mathrm{c}}$ & 3.86 & 3.99 & 4.14 & 4.20 & 4.30 & 4.33 & 4.36 & 4.44 & 4.41 & 4.50 \\
\hline \multirow{2}{*}{124.5} & $\mathrm{Ef}_{\mathrm{t}}$ & 3.78 & 4.53 & 5.33 & 7.27 & 8.44 & 9.65 & 13.11 & 14.96 & 17.33 & 22.98 \\
\hline & $\mathrm{Ef}_{\mathrm{c}}$ & 8.20 & 8.34 & 8.67 & 8.91 & 9.05 & 8.96 & 9.35 & 9.30 & 9.45 & 9.60 \\
\hline
\end{tabular}


Saad A. El-Hamrawy and Ahmed I. Abu El-Maaty, "Effect of Excess Axle Loads and High Tire ..."

Tables (2): LEF \& Tire Pressure for Tandem Axle Load with Dual Tires at E subgrade $=58 \mathrm{~N} / \mathrm{mm}^{2}$.

\begin{tabular}{|c|c|c|c|c|c|c|c|c|c|c|c|}
\hline \multirow{2}{*}{$\begin{array}{l}\text { Axle load } \\
(\mathrm{kN})\end{array}$} & \multirow{2}{*}{ LEF } & \multicolumn{10}{|c|}{ Tire Contact Pressure $\left(\mathrm{N} / \mathrm{mm}^{2}\right)$} \\
\hline & & 0.50 & 0.55 & 0.60 & 0.70 & 0.75 & 0.80 & 0.85 & 0.90 & 1.00 & 1.10 \\
\hline \multirow{2}{*}{80.0} & $\mathrm{Ef}_{\mathrm{t}}$ & 0.16 & 0.19 & 0.23 & 0.29 & 0.34 & 0.25 & 0.32 & 0.37 & 0.42 & 0.55 \\
\hline & $\mathrm{Ef}_{\mathrm{c}}$ & 0.05 & 0.05 & 0.05 & 0.05 & 0.05 & 0.05 & 0.05 & 0.05 & 0.05 & 0.05 \\
\hline \multirow{2}{*}{115.6} & $\mathrm{Ef}_{\mathrm{t}}$ & 0.50 & 0.58 & 0.73 & 0.96 & 1.09 & 1.26 & 1.49 & 1.71 & 1.85 & 2.17 \\
\hline & $\mathrm{Ef}_{\mathrm{c}}$ & 0.30 & 0.29 & 0.31 & 0.31 & 0.30 & 0.32 & 0.30 & 0.32 & 0.32 & 0.32 \\
\hline \multirow{2}{*}{133.5} & $E f_{t}$ & 0.74 & 0.91 & 1.09 & 1.49 & 1.71 & 1.91 & 2.45 & 2.68 & 2.97 & 3.39 \\
\hline & $E f_{c}$ & 0.61 & 0.60 & 0.62 & 0.62 & 0.63 & 0.61 & 0.65 & 0.64 & 0.65 & 0.61 \\
\hline \multirow{2}{*}{148.0} & $\mathrm{Ef}_{\mathrm{t}}$ & 1.00 & 1.20 & 1.49 & 2.07 & 2.38 & 2.68 & 3.39 & 3.74 & 4.12 & 4.84 \\
\hline & $\mathrm{Ef}_{\mathrm{c}}$ & 1.00 & 0.97 & 1.03 & 1.05 & 1.06 & 1.06 & 1.07 & 1.08 & 1.09 & 1.08 \\
\hline \multirow{2}{*}{187.0} & $\mathrm{Ef}_{\mathrm{t}}$ & 1.44 & 1.79 & 2.17 & 3.02 & 3.49 & 4.01 & 4.91 & 5.59 & 6.27 & 7.37 \\
\hline & $\mathrm{Ef}_{\mathrm{c}}$ & 1.92 & 1.95 & 1.95 & 2.01 & 2.03 & 2.05 & 1.97 & 2.05 & 2.09 & 2.06 \\
\hline \multirow{2}{*}{258.0} & $\mathrm{Ef}_{\mathrm{t}}$ & 3.16 & 3.43 & 3.51 & 3.64 & 3.74 & 3.71 & 3.94 & 3.92 & 3.99 & 4.06 \\
\hline & $\mathrm{Ef}_{\mathrm{c}}$ & 9.53 & 10.45 & 10.51 & 11.00 & 11.19 & 11.00 & 11.44 & 11.25 & 11.57 & 11.57 \\
\hline \multirow{2}{*}{275.8} & $E f_{t}$ & 4.18 & 5.38 & 6.68 & 9.68 & 11.35 & 13.10 & 17.24 & 19.48 & 21.30 & 26.59 \\
\hline & $\mathrm{Ef}_{\mathrm{c}}$ & 14.11 & 14.73 & 15.04 & 15.45 & 15.78 & 15.53 & 16.28 & 16.28 & 16.03 & 16.72 \\
\hline
\end{tabular}


contact pressure of $0.5 \mathrm{~N} / \mathrm{mm}^{2}$ may produce under designed pavement sections. For pavement design purposes a single value of equivalent factors should be used. Thus, the greater load equivalency factors between Eft and Efc for single and tandem axle loads were listed in Tables (4) to (7) respectively. From these tables, it can be noticed that the values of the LEFs in Tables (4) to (7) at the operational level of tire contact pressure of $0.8 \mathrm{~N} / \mathrm{mm} 2$ along with the legal values of axle loads in Egypt are approximately twice and triple AASHTO LEFs for single and tandem axle loads . Tables (4) to (7) obtain the highest values of fatigue and rutting load equivalency factors (LEFs) for single and tandem axle loads at two subgrade elastic modulus. It can be concluded that at the same tire pressures and axle loads, increased subgrade elastic modulus had insignificant influence on LEFs.

\subsection{Relationship between LEF Using BISAR Computer Program and LEF of AASHTO Specification}

Linear regression was performed between the highest values of calculated LEFs at $0.50 \mathrm{~N} / \mathrm{mm} 2$ tire pressure at different modulus of elasticity of subgrade for both single and tandem axle loads. A very strong correlation between the calculated LEFs and AASHTO-LEFs was found. The regression equation is as follows:

$$
\mathrm{Y}=\mathrm{a} 0 \mathrm{X}+\mathrm{a} 1
$$

Where:

Y: calculated LEF ; X: AASHTO- LEFs; a0 and a1 are constants. Tables (8) and (9) represent the two constants (a0 and a1) and the correlation coefficients for both single and tandem axle loads. From these tables, it can be concluded that at lower modulus of elasticity of subgrade $(58 \mathrm{~N} / \mathrm{mm} 2)$, higher constant $(\mathrm{a} 0)$ is achieved.
On the other hand, no specific trend can be seen for the variation of the coefficient a1 with increasing in the modulus of elasticity of subgrade.

Tables (3): AASHTO LEF for Single and Tandem Axle Load [2].

\begin{tabular}{|c|c|c|c|}
\hline \multicolumn{4}{|c|}{ AASHTO LEF } \\
\hline \multicolumn{2}{|c|}{ Single Axle Load } & \multicolumn{2}{|c|}{$\begin{array}{c}\text { Tandem Axle } \\
\text { Load }\end{array}$} \\
\hline $\begin{array}{l}\text { Load } \\
(\mathrm{kN})\end{array}$ & LEF & $\begin{array}{l}\text { Load } \\
(\mathrm{kN})\end{array}$ & LEF \\
\hline 35.6 & 0.0343 & 80 & 0.077 \\
\hline 44.5 & 0.0877 & 97.8 & 0.18 \\
\hline 53.4 & 0.189 & 115.6 & 0.363 \\
\hline 62.3 & 0.36 & 133.5 & 0.658 \\
\hline 71.2 & 0.623 & 148 & 1 \\
\hline 80 & 1 & 169 & 1.7 \\
\hline 89 & 1.51 & 187 & 2.51 \\
\hline 97.8 & 2.18 & 204.5 & 3.55 \\
\hline 106.8 & 3.03 & 222.4 & 4.86 \\
\hline 115.6 & 4.09 & 240.2 & 6.47 \\
\hline 124.5 & 5.39 & 258 & 8.45 \\
\hline 133.5 & 6.79 & 275.8 & 10.84 \\
\hline 142.3 & 8.88 & & \\
\hline 151.2 & 11.18 & & \\
\hline 160 & 13.93 & & \\
\hline
\end{tabular}

Table (4): The Highest LEF for Single Axles at E subgrade $=58 \mathrm{~N} / \mathrm{mm}^{2}$.

\begin{tabular}{|c|c|c|c|c|c|c|c|c|c|c|}
\hline \multirow{2}{*}{$\begin{array}{l}\text { Axle } \\
\text { Load } \\
(\mathrm{kN})\end{array}$} & \multicolumn{10}{|c|}{ Tire Contact Pressure $\left(\mathrm{N} / \mathrm{mm}^{2}\right)$} \\
\hline & 0.50 & 0.55 & 0.60 & 0.70 & 0.75 & 0.80 & 0.85 & 0.90 & 1.00 & 1.10 \\
\hline 35.6 & 0.24 & 0.36 & 0.54 & 1.19 & 1.65 & 2.31 & 4.16 & 5.52 & 7.04 & 11.33 \\
\hline 71.2 & 0.75 & 0.95 & 1.21 & 1.96 & 2.48 & 3.09 & 5.20 & 6.04 & 8.27 & 13.49 \\
\hline 80 & 1.00 & 1.26 & 1.58 & 2.41 & 3.01 & 3.69 & 5.58 & 6.82 & 8.44 & 14.69 \\
\hline 106.8 & 3.86 & 3.99 & 4.14 & 4.75 & 5.64 & 6.67 & 9.17 & 10.78 & 12.61 & 17.33 \\
\hline 124.5 & 8.20 & 8.34 & 8.67 & 8.91 & 8.44 & 9.65 & 13.11 & 14.96 & 17.33 & 22.98 \\
\hline 142.3 & 15.31 & 15.42 & 16.18 & 16.97 & 16.97 & 16.97 & 18.30 & 20.71 & 23.37 & 30.00 \\
\hline 160 & 27.25 & 27.93 & 27.93 & 29.15 & 29.15 & 30.42 & 31.73 & 31.73 & 32.26 & 40.16 \\
\hline
\end{tabular}


Table (5): The Highest LEF for Single Axles at E subgrade $=87 \mathrm{~N} / \mathrm{mm}^{2}$.

\begin{tabular}{|c|c|c|c|c|c|c|c|c|c|c|}
\hline \multirow{2}{*}{$\begin{array}{l}\text { Axle } \\
\text { Load } \\
(\mathrm{KN})\end{array}$} & \multicolumn{10}{|c|}{ Tire Contact Pressure (N/mm2) } \\
\hline & 0.50 & 0.55 & 0.60 & 0.70 & 0.75 & 0.80 & 0.85 & 0.90 & 1.00 & 1.10 \\
\hline 35.6 & 0.24 & 0.38 & 0.57 & 1.25 & 1.77 & 2.45 & 4.39 & 5.83 & 7.47 & 11.96 \\
\hline 71.2 & 0.75 & 0.97 & 1.23 & 1.99 & 2.52 & 3.20 & 5.77 & 6.39 & 8.69 & 13.99 \\
\hline 80 & 1.00 & 1.27 & 1.60 & 2.45 & 3.04 & 3.78 & 6.04 & 7.07 & 9.16 & 15.70 \\
\hline 106.8 & 3.86 & 3.99 & 4.15 & 4.72 & 5.63 & 6.69 & 9.36 & 11.03 & 12.94 & 17.89 \\
\hline 124.5 & 8.20 & 8.31 & 8.60 & 8.90 & 9.03 & 9.65 & 13.20 & 15.11 & 17.56 & 23.40 \\
\hline 142.3 & 15.31 & 15.40 & 15.88 & 16.66 & 17.07 & 17.27 & 18.22 & 20.87 & 23.40 & 30.21 \\
\hline 160 & 27.25 & 27.25 & 28.15 & 29.39 & 29.39 & 30.19 & 31.16 & 31.50 & 32.26 & 40.37 \\
\hline
\end{tabular}

Table (6): The Highest LEF for Tandem Axles at E subgrade $=58 \mathrm{~N} / \mathrm{mm}^{2}$.

\begin{tabular}{||c||c|c|c|c|c|c|c|c|c|c||}
\hline \hline \multicolumn{1}{||c||}{$\begin{array}{c}\text { Axle } \\
\text { Load } \\
(\mathrm{KN})\end{array}$} & \multicolumn{10}{c||}{ Tire Contact Pressure (N/mm2) } \\
\cline { 2 - 13 } & 0.50 & 0.55 & 0.60 & 0.70 & 0.75 & 0.80 & 0.85 & 0.90 & 1.00 & 1.10 \\
\hline 80 & 0.16 & 0.19 & 0.23 & 0.29 & 0.34 & 0.25 & 0.32 & 0.37 & 0.42 & 0.55 \\
\hline 115.6 & 0.50 & 0.58 & 0.73 & 0.96 & 1.09 & 1.26 & 1.49 & 1.71 & 1.85 & 2.17 \\
\hline 133.5 & 0.74 & 0.91 & 1.09 & 1.49 & 1.71 & 1.91 & 2.45 & 2.68 & 2.97 & 3.39 \\
\hline 148 & 1.00 & 1.20 & 1.49 & 2.07 & 2.38 & 2.68 & 3.39 & 3.74 & 4.12 & 4.84 \\
\hline 187 & 1.92 & 1.95 & 2.17 & 3.02 & 3.49 & 4.01 & 4.91 & 5.59 & 6.27 & 7.37 \\
\hline 258 & 9.53 & 10.45 & 10.51 & 11.00 & 11.19 & 11.00 & 11.44 & 11.25 & 11.57 & 11.57 \\
\hline 275.8 & 14.11 & 14.73 & 15.04 & 15.45 & 15.78 & 15.53 & 17.24 & 19.48 & 21.30 & 26.59 \\
\hline
\end{tabular}

Table (7): The Highest LEF for Tandem Axles at E subgrade $=87 \mathrm{~N} / \mathrm{mm}^{2}$.

\begin{tabular}{||c||c|c|c|c|c|c|c|c|c|c||}
\hline \multicolumn{1}{|c|}{$\begin{array}{c}\text { Axle } \\
\text { Load } \\
(\mathrm{KN})\end{array}$} & \multicolumn{10}{c||}{ Tire Contact Pressure $\left(\mathrm{N} / \mathrm{mm}^{2}\right)$} \\
\cline { 2 - 13 } & 0.50 & 0.55 & 0.60 & 0.70 & 0.75 & 0.80 & 0.85 & 0.90 & 1.00 & 1.10 \\
\hline 80 & 0.17 & 0.20 & 0.23 & 0.30 & 0.34 & 0.26 & 0.27 & 0.31 & 0.43 & 0.57 \\
\hline 115.6 & 0.50 & 0.59 & 0.74 & 1.00 & 1.12 & 1.29 & 1.53 & 1.75 & 1.90 & 2.23 \\
\hline 133.5 & 0.75 & 0.91 & 1.12 & 1.53 & 1.75 & 1.93 & 2.49 & 2.77 & 3.03 & 3.46 \\
\hline 148 & 1.00 & 1.20 & 1.50 & 2.09 & 2.41 & 2.73 & 3.46 & 3.82 & 4.21 & 4.96 \\
\hline 187 & 1.92 & 1.96 & 2.16 & 3.03 & 3.56 & 4.04 & 5.03 & 5.67 & 6.37 & 7.50 \\
\hline 258 & 9.18 & 10.40 & 10.47 & 11.01 & 11.17 & 11.01 & 11.49 & 11.33 & 11.66 & 11.58 \\
\hline 275.8 & 13.97 & 14.65 & 14.95 & 15.46 & 15.77 & 15.56 & 17.39 & 19.49 & 21.56 & 27.01 \\
\hline \hline
\end{tabular}

- 388 - $\quad$ Engineering Research Journal, Minoufiya University, Vol. 35, No. 4, October 2012 
Table (8): Constants for Single Axle Loads.

\begin{tabular}{|c|c|c|c|}
\hline $\mathrm{E}\left(\mathrm{N} / \mathrm{mm}^{2}\right)$ & $\mathrm{a}_{0}$ & $\mathrm{a}_{1}$ & Corr. Coeff \\
\hline 58 & 1.893 & -0.921 & 0.984 \\
\hline 72.5 & 1.891 & -0.807 & 0.986 \\
\hline 87 & 1.885 & -0.814 & 0.986 \\
\hline
\end{tabular}

\subsection{Relationships for LEF}

Multi-regression was fulfilled to obtain the relationships between LEFs and axle loads, tire contact pressure and subgrade elastic modulus for single and tandem axles. The achieved relations are as follows:

For single axle loads:

$\mathrm{LEF}=20.65 \mathrm{Pt}+0.188 \mathrm{P}+0.005 \mathrm{E}-24.47 \quad \mathrm{R}^{2}=0.80$

For tandem axle loads:

$\mathrm{LEF}=9.07 \mathrm{Pt}+0.103 \mathrm{P}+0.001 \mathrm{E}-18.42 \quad \mathrm{R}^{2}=0.83$

Where:

LEF: Load equivalency factor; Pt: tire contact pressure $\left(\mathrm{N} / \mathrm{mm}^{2}\right) ; \mathrm{P}$ : axle load $\left(\mathrm{N} / \mathrm{mm}^{2}\right) ;$ E: Subgrade elastic modulus $\left(\mathrm{N} / \mathrm{mm}^{2}\right)$.

\section{Conclusions}

Based on the methodology and analysis of results of this study, the following conclusions were drawn:

1. As the axle load increased, high tire pressure could cause significant increase in the equivalent axle load factor, while fatigue failure was the prevailing failure mode. As the axle load continued to increase, the failure mode turned to a rutting one and, in this case the effect of increase in tire pressure could be ignored.

2. The influence of high tire pressure on asphalt pavement is depended on axle load. At low to intermediate axle loads, high tire pressure could cause marked increase in LEF. At high axle loads, variation of equivalency factor with tire pressure could be neglected. At the same tire pressures and axle loads, increased subgrade elastic modulus had insignificant influence on LEFs.

3. LEFs could be determined as a function of axle loads , tire contact pressure and subgrade elastic modulus .

4. The values of the LEFs in at the operational level of tire pressure of $0.8 \mathrm{~N} / \mathrm{mm}^{2}$ along with the legal values of axle loads in Egypt were approximately twice and triple AASHTO LEFs for single and tandem axle loads.

5. A very strong correlation between the calculated LEFs and AASHTO-LEFs was found. At lower modulus of elasticity of subgrade, higher constant $\left(\mathrm{a}_{0}\right)$ was achieved. On the other hand, no specific trend can be seen for the variation of the coefficient $a_{1}$ with increasing in the modulus of elasticity of subgrade

6. The linear elastic BISAR computer program could be used successfully to calculate the flexible pavement responses and to evaluate the behavior of pavement sections under different conditions axle loads, and tire pressure.
Table (9): Constants for Tandem Axle Loads.

\begin{tabular}{|c|c|c|c|}
\hline $\mathrm{E}(\mathrm{N} / \mathrm{mm} 2)$ & $\mathrm{a}_{0}$ & $\mathrm{a}_{1}$ & Corr. Coeff \\
\hline 58 & 1.740 & -0.666 & 0.987 \\
\hline 72.5 & 0.648 & -0.648 & 0.986 \\
\hline 87 & 0.642 & -0.642 & 0.986 \\
\hline
\end{tabular}

\section{References}

[1]. Egyptian Code for Urban and Rural Roads , Part 6:

Highway Structure Design, first edition, El-Ahram press , 2010 .

[2]. M.E.Abdel-Motaleb, Impact of High Pressure Truck Tires on Pavement Design in Egypt, Emirates Journal for Engineering Research, Vol. 12, No.2, United Arab Emirates, pp 172-186,2007.

[3]. T. D. Gillespi and S. M. Karimihas, Effects of Heavy Vehicle Characteristics on Pavement Response and Performance, Transportation Research Board, Washington, D.C., 2000.

[4] H.M.A.Salem, "Effect of Excess Axle Weights on Pavement Life", Emirates Journal for Engineering Research, Vol.13, No1, May, 2008.

[5] B.S Morton, E. Luttig, E. Horak and A.T. Visser, "The Effect of Axle Load Spectra and Tire Inflation Pressures on Standard Pavement Design Methods", 8th Conference on Asphalt Pavements for Southern Africa , Sun City, Southern Africa, September, pp 95-102, 2004.

[6]. K. Gomma, and S. El-Hamrawy, Load Equivalence Factors as Function of Axial Loads and Tire Pressure for Design of Flexible Pavement, Alexandria Journal, Vol. 42, No.4, July, pp 212-218, 2003.

[7]. Yung-Sheng Chang, The Performance-based Pavement Evaluation and Effect of Non-uniform Contact Stresses on Flexible Pavement, M.SC. Thesis in Civil Engineering, Central State University, China, 2005.

[8] HUI- ZONG JIANG, Subgrade Soil Moisture Influence on Pavement Performance, M.SC.Thesis in Civil Engineering, Civil Engineering Research Institute, National Central University, China, 2008.

[9] Minkwan Kim, "Three-Dimensional Finite Element Analysis of Flexible Pavements Considering Nonlinear Pavements Foundation Behavior", Ph.D. Dissertation in Civil Engineering, University of Illinois, Urbana, USA, 2007.

[10] David Roylance, "Finite Element Analysis", Department of Materials Science and Engineering, Massachusetts Institute of Technology, Cambridge, February, 2001.

[11]. M.E. Abdel-Motaleb, Flexible Pavement Components for Optimum Performance in Rutting and Fatigue, Zagazig University, Egypt, pp 114-120, 2009. 